\title{
O VALOR DEMOCRÁTICO DA EDUCAÇÃO NO JOVEM FLORESTAN FERNANDES
}

\section{THE DEMOCRATIC VALUE OF EDUCATION IN THE YOUNG FLORESTAN FERNANDES}

\author{
SOUZA, Alexandre ${ }^{1}$
}

\section{RESUMO}

O artigo trata da abordagem sobre educação e democracia por Florestan Fernandes, em sua juventude. $\mathrm{O}$ objetivo é identificar na obra sociológica/educacional de Fernandes, a indicação da educação como um valor e sua relação com o ideal democrático dos anos de 1950. Interessa a compreensão desse ideal construído pelo autor, período de sua juventude. Época marcada por uma série de mobilizações, pela democratização da educação e da vida social do país. Tratou-se de uma pesquisa simultaneamente bibliográfica e biográfica ancorada nos textos sócio educacionais de/e sobre Florestan Fernandes e quanto ao período de 1950, no Brasil. Redescobre-se um jovem professor militante inspirado pelos acontecimentos do seu tempo, em busca de horizontes capazes de responder suas angústias, por meio da solidariedade e na possibilidade de existências de si e do outro.

PalAVRAS-CHAVE: Educação; Democracia; Florestan Fernandes.

\begin{abstract}
The article deals with Florestan Fernandes' approach to education and democracy in his youth. The objective was to identify in his sociological / educational work an indication of education as a value and its relation to the democratic ideals of the 1950s. Our interest was to understand the construction of his ideal in his youth, an epoch period marked by a series of mobilizations, by democratization of education and social life of the country. The research was both bibliographical and biographical anchored in socio-educational texts by / and about Florestan Fernandes as well as on the 1950s in Brazil. We rediscover a young militant teacher who was inspired by the events of his time and was searching for new horizons which would respond to his anguishes.
\end{abstract}

KEYWORDS: Education; Democracy; Florestan Fernandes.

1 Universidade do Estado do Rio de Janeiro. Mestrando em Educação. e-mail: augustoesouza@gmail.com 


\section{INTRODUÇÃO}

A educação como um valor é uma discussão pouco presente sobre os textos do jovem Florestan Fernandes. O debate realizado por Fernandes transcende, para sua época, anos de 1950, os sentidos usualmente construídos para a educação, período histórico da abordagem. Está se diante de uma construção ideal, que vai além da projeção de funções e objetivos para a educação. Explicita-se a ideia de educação do jovem Florestan Fernandes para além da materialidade, dimensão muito discutida quando se trata dos debates sobre a educação, no período histórico citado. Evocação quase sempre pensada quando se discute um autor marxista.

O que se quer é debater a peculiar trajetória de vida e os ideais do jovem Florestan, em especial sobre a educação e a democracia. Não se trata de divulgar um autor, um acadêmico, seus títulos. Quer-se bem mais um Florestan do que um Fernandes. Um personagem que até pouco tempo foi pouco discutido pelos biógrafos. Um jovem Florestan Fernandes redescoberto. Um professor que em suas movimentações, na construção do seu cotidiano, buscou um sentido para a educação e encontrou-a como valor democrático.

\section{SOBRE A DÉCADA DE 1950}

A pesquisa considerou a dimensão biográfica e histórica como partes integrantes para identificar o valor democrático da educação em Florestan. Desse modo consideram-se dimensões distintas não constituindo uma contradição teóricometodológica e nem um ecletismo epistemológico. Entende-se que as dimensões histórica e cotidiana são partes de um mesmo processo, para compreensão de uma sociedade, quanto as suas transformações.

Ao citar um período histórico sabe-se a dificuldade de captar um momento, em extrair sínteses que direcionem o trabalho de pesquisa. Observa-se a dificuldade de tratar o tempo e o desafio de caracterizá-lo. É sabido que cortes temporais trazem certas problemáticas, visto que acontecimentos não podem ser compreendidos aos pedaços, possuem lastros e "Pode estender-se por uma larga duração. [...] pode concentrar-se em uma conjuntura delimitada" (IANNI, 2004, p. 342).

A década de 1950 é um período especial para compreensão de alguns acontecimentos na educação do país, bem como sobre o jovem professor Florestan e seus ideários. Para essa busca recorre-se à tese de Débora Mazza defendida em 1997, no Programa de Pós-Graduação em Educação, na Universidade Estadual de Campinas (Unicamp) denominada, A produção sociológica de Florestan Fernandes $e$ a problemática educacional: uma leitura (1941-1964).

Observa-se (MAZZA, 1997), os contornos sociais de um período, a partir da ocorrência de inúmeras subversões populares. Ao contornar um período histórico, 
DOI: 10.12957/e-mosaicos.2018.30062

não se quer estratificar uma época. Pelo contrário é um risco afirmar que algo é aquilo ou isso, já que toda época fica circunscrita por 'linhas de vapor', desfeitas por um 'sopro'. Pretende-se compreender a atmosfera de um período no Brasil. Quando afirma-se ser um período de subversões, década de 1950, pretende-se conhecer esse período enquanto época de esgarçamento dos limites do pensar e do agir. Aos fatos destaca-se que:

O período de 1945 a 1964 teria se caracterizado como outra fase de retomada de experiências democráticas na história da sociedade brasileira. [...] uma nova era de reconstrução de governos populares e democráticos [...] uma redemocratização das instituições políticas com a ampliação da participação dos diversos setores sociais. [...] mobilização e politização crescente dos setores populares sugeriam novos equacionamentos reflexivos sobre a realidade brasileira. Florestan Fernandes [teria] se beneficiado deste patamar sócio histórico que ofereceu novas composições explicativas da realidade brasileira (MAZZA, 1997, p. 32-34. Grifo meu).

O período acima destacado possibilita 'sentir' a atmosfera de uma época, sem fixar estereótipos. Clarifica os passos da pesquisa dando segurança a proposta de discussão, sobre o valor democrático da educação em Florestan Fernandes. Uma citação que abrange ações complexas e instigantes. Retomar, reconstruir, ampliar, mobilizar, equacionar e compor. Todos os verbos destacados indicam algo em construção, em processo, um desejo de novo, de inusitado. É sobre esse contexto histórico que se propõe expor o pensamento de Florestan Fernandes, sobre a educação como um valor.

\section{FLoReStan FERNANDES, EDUCAÇÃo VIVIDA}

Para alcançar o ideário do jovem Florestan Fernandes deve-se seguir seus passos, observá-los e entusiasmar-se com eles. Momento biográfico do artigo, em que se pretende enfatizar a 'trajetória ímpar' de Florestan. Destaca-se a experiência educacional como aluno nos anos de 1930 e 1940, com repercussões no tempo de investigação, anos de 1950. A 'trajetória ímpar' de Florestan Fernandes pode ser descrita através de dois fragmentos textuais que dimensionam seu processo educativo: 
Se eu tinha pouco tempo para aproveitar a infância, nem por isso deixava de sofrer o impacto humano da vida nas trocinhas e de ter résteas de luz que vinham pela amizade que se forma por meio do companheirismo (nos grupos de folguedos, de amigos de vizinhança, dos colegas que se dedicavam ao mesmo mister, como meninos de rua, engraxates, entregadores de carne, biscateiros, aprendizes de alfaiate e por aí a fora). (FERNANDES, 1977, p.143 apud OLIVEIRA, 2010, p.12).

O que me foi importante, porque no desespero de romper a castração cultural invisível foi por aí que eu próprio abri o meu caminho, formando uma curiosa cultura letrada, que ia do Tico-Tico à literatura de cordel, aos livros de piada, e a uma variadíssima literatura "erudita", na qual prevaleciam os livros didáticos e de história, vendidos nos sebos, e os romances. Se a cidade continha alguma civilização, eu me tornei seu adepto e seu afilhado pelo autodidatismo (FERNANDES, 1977, p.146 apud OLIVEIRA, 2010, p.12).

A biografia de Florestan Fernandes foi constituída por meio de relatos improvisados ao longo de sua vida, especificamente quando o autor já se consolidava como reconhecido sociólogo, professor universitário e educador. Fernandes pensou, militou e escreveu sobre educação desde os anos de 1950 até os últimos anos de sua vida, década de 1990. Pode-se distinguir três períodos de sua produção educacional. Destaca-se, a seguir, o período inicial dessa produção.

Os primeiros textos educacionais de Fernandes estiveram vinculados a uma agenda de discussões, decorrente de intensa movimentação social ocorrida nos anos de 1950. Textos escritos nesse período estão presentes no livro, Educação $e$ Sociedade no Brasil lançado em 1966 pela editora da Universidade de São Paulo. Tratar da educação (FERNANDES, 1966) não significava remeter-se propriamente ao universo escolar, espaço priorizado para essas discussões. Na visão de Florestan a educação estava na cultura, nas anedotas contadas pelas crianças italianas e sírias recém-imigradas ao Brasil e no folclore vivenciado nas ruas de São Paulo. A educação estava intimamente ligada ao cotidiano de seu tempo e poderia ser observada nas relações de compartilhamento, em sensações, percepções e representações entre as pessoas. Um entendimento, digamos, com fronteiras amplas para tratar de questões educacionais.

$\mathrm{Na}$ trajetória biográfica de Florestan Fernandes destacam-se dois fragmentos de textos no livro, Educação e Sociedade no Brasil. São textos importantes para o entendimento da ideia de educação como um valor. No primeiro fragmento há uma síntese de todas as sensações vividas pelo autor, ao longo de sua dolorosa jornada formativa. Florestan Fernandes faz uma 'transferência' das lutas que travou para educar-se àqueles que apostaram tudo na educação como uma rota de fuga. No 
e-Mosaicos - Revista Multidisciplinar de Ensino, Pesquisa, Extensão e Cultura do Instituto de Aplicação Fernando Rodrigues da Silveira (CAp-UERJ) V. 7 - N. 14 - ABRIL 2018 - ISSN: 2316-9303

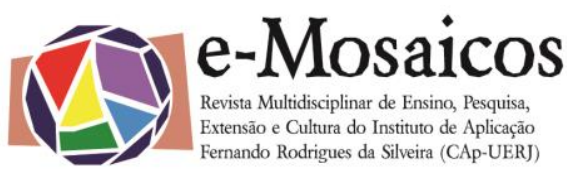

DOI: $10.12957 /$ e-mosaicos.2018.30062

segundo fragmento de texto o autor expõe suas ideias entendendo a educação como intrínseca à vida social. Afirma o autor:

Minha disposição de inconformismo achava fundamento na própria situação de existência. Tudo se passou como se transformasse, de um momento para outro, em porta-voz das frustrações e da revolta dos meus antigos companheiros da infância e da juventude. O meu estado de espírito fez com que o professor universitário falasse em nome do filho da antiga criada e lavadeira portuguesa, o qual teve de ganhar a vida antes mesmo de completar sete anos, engraxando sapatos ou dedicando-se a outras ocupações igualmente degradadas [...] coube-me o dever de elevar ao mundo [...] as angústias, os sentimentos e as obsessões dos esbulhados, e honro-me ao lembrar que não trepidei, por um instante, diante dos imperativos desse dever [...] nunca deixei de considerar-me como o representante fortuito dos interesses e dos valores educacionais das massas populares. Nunca fiz isso por qualquer intuito calculado ou inconsciente do 'modernismo' (FERNANDES, 1966, p. 19-21).

Florestan viveu uma época em que as máquinas eram inseridas no trabalho diário. O cotidiano tornava-se célere. Nossa personagem passou por várias ocupações em sua juventude como engraxate, garçom e vendedor de produtos farmacêuticos. Nos raros momentos de folga lia nas bibliotecas próximas de seu local de trabalho e no próprio trabalho.

O que está em jogo ainda não é a realização de investigações sistemáticas, cuidadosas e demoradas sobre a realidade educacional brasileira. Mas, estabelecer uma ligação definida entre o que fazemos e 0 que deveríamos fazer [...] [é preciso] ter a coragem de improvisar - de extrair de suas experiências diretas, do conhecimento do senso comum [...] reflexões que permitam alargar a nossa compreensão da realidade e do sentido das "exigências da situação". (FERNANDES, 1966, p. 15-16. Grifo do autor).

Observa-se nas duas passagens textuais acima apresentadas, que qualquer exigência educativa passava pela exigência vivida. São as mazelas da vida que pautam as necessidades educativas. Florestan Fernandes não rejeitou os estudos sistemáticos, as investigações sobre os problemas educacionais, pelo contrário. Florestan sentia-se aflito ao ver a vida de seus amigos esvaecerem. Pela educação entendia que era possível formar elos de solidariedade entre os 'esbugalhados'. Para orientar-se no mundo é preciso existir e a educação tornava-se possiblidade dessa existência. 


\section{UM SENTIDO DE DEMOCRACIA PARA FLORESTAN}

O entendimento de democracia para o jovem Florestan encontrava-se para além do aspecto quantitativo ou jurídico. A democracia deveria apresentar dois aspectos fundamentais. O primeiro aspecto refere-se a presença de vínculos de solidariedade entre os desprotegidos e alijados da vida social. O segundo aspecto trata da garantiria pela espontaneidade e valorização de expressões construídas no cotidiano.

Florestan não conceitua a democracia e nem utiliza definições históricas, não faz referência à democracia formal. A democracia no jovem Florestan foi constituída em um período que a sociedade brasileira tinha como pauta temas alçados por inúmeras mobilizações sociais. Florestan assimilou a atmosfera de sua época encontrando na democracia e na educação o sentido de 'sobrevida'. Florestan destacou esse sentimento, em evento da Associação Nacional de Pós-Graduação e Pesquisa em Ciências Sociais, em que dizia: "[...] minha mãe deu o nome de Florestan e a minha madrinha dizia que Florestan não era nome para mim [...]. E eu fiquei Vicente para a família de minha madrinha, e para a minha própria família [...]". (ANPOCS, 1995, p.7),

Observa-se que (SOUZA, 2007, p.85, Grifos meus), "[...] a questão da democracia [em Florestan] aparece concatenada a outros temas que lhe foram caros [...] e não [pode ser compreendida] somente como uma forma de organização política". De acordo com a autora, a democracia por Florestan Fernandes "[...] só poderia se realizar quando o povo emergisse em cena e passasse a participar da história como sujeito". (SOUZA, 2007, p.87). O ideal democrático de Fernandes estava despido de qualquer formalidade conceitual. A democracia deveria permear todas as esferas da vida, tal como a educação. Nossa personagem não acreditava e nem enxergava um papel dado para essas esferas da vida social. Esses 'papéis' seriam construídos nas relações da vida diária.

Jovem professor da Universidade de São Paulo, Florestan vivenciou a ingenuidade daqueles que experimentavam a inédita democracia burguesa, numa sociedade autocrática. Uma experimentação singular sobre um sistema político em implementação, ou em transplantação, como Fernandes posteriormente viria afirmar.

A democracia e a educação não pareciam ter fronteiras entre si. Para Florestan Fernandes correspondiam a duas dimensões que interagiam com a vida diária. Destaca-se e valoriza-se a consagração da vida comum, sem apagar as frágeis condições de sobrevivência, em uma sociedade desigual.

\section{CONSIDERAÇões FinaIS}

Ao longo do artigo evidencia-se um aspecto que, em síntese, pode revelar um jovem Florestan e a maneira com que lidava com as questões educacionais. 
DOI: 10.12957/e-mosaicos.2018.30062

Observou-se (SAVIANI, 1996, p.72. Grifo meu), a "[...] radicalidade com que Florestan Fernandes assumiu a condição humana [e que] o levou a assumir também radicalmente as atividades em que se empenhou [...]". Para o jovem Florestan a vida não pedia passagem, estava ali para ser desesperadamente agarrada. $O$ autor acreditava que havia "[...] uma espécie de processo educativo permanente nas relações sociais em crise" (MARTINS, 1996, p.19).

Para Miriam Cardoso socióloga e professora aposentada pela Universidade Federal do Rio de Janeiro ressalta-se (CARDOSO, 1995, p.09) "[...] o posicionamento socialmente comprometido de Florestan". Segundo a autora, Fernandes foi um militante engajado para a transformação social e desenvolveu um trabalho intelectual e militante em prol da maioria despossuída. Posicionamento que o autor cultivou ao longo de sua vida, nas críticas direcionadas para a ordem social patrimonialista e autocrática.

Acrescentam-se os aspectos biográficos sobre Florestan Fernandes, para o alcance do propósito do artigo, indo além de obras acadêmicas. Biografia que 'contraria' a História, como é o caso da biografia de Florestan Fernandes. Uma biografia do desencontro, "[...] na riqueza explicativa que há na história de vida dos que se insurge contra o destino traçado [...]. " (MARTINS, 1996, p.16). Mais ainda, pois:

Florestan Fernandes, tinha ele especial preocupação teórica e histórica com a biografia. Não só porque a história pessoal reconstruída na perspectiva do método da história de vida constitui rico documento sociológico, mas também porque em seu entender o homem, inclusive o homem comum, tem de algum modo à possibilidade de intervir ativamente nos processos sociais que protagoniza (MARTINS, 1996, p.14. Grifo meu)."

Um jovem personagem/protagonista que dissecava a si mesmo, no intuito de ver um sentido educativo ao longo de sua formação. Esse caminho foi percorrido a partir de um profundo desencontro entre o fora de si e o dentro de si educativo.

\section{REFERÊNCIAS}

ASSOCIAÇÃO NACIONAL DE PÓS-GRADUAÇÃO E PESQUISA EM CIÊNCIAS SOCIAIS (ANPOCS). Florestan Fernandes: esboço de uma trajetória. In: Boletim Informativo e Bibliográfico de Ciências Sociais. Rio de Janeiro, n. 40, p. 3-25, jul./dez. 1995.

CARDOSO, Miriam. Em memória de Florestan Fernandes. In: Estudos Avançados, São Paulo, n.25, p.07-10, set./dez. 1995.

FERNANDES, Florestan. Educação e sociedade no Brasil. São Paulo: Dominus, 1966. 
IANNI, Octavio. Florestan Fernandes e a formação da sociologia brasileira. In: . Florestan Fernandes: sociologia crítica e militante. São Paulo: Expressão Popular, 2004. pp 46-74.

MARTINS, José. Vida e história na sociologia de Florestan Fernandes: reflexões sobre o método da história de vida. In: Revista USP, São Paulo, n.29, p.14-19, 1996.

MAZZA, Débora. A produção sociológica de Florestan Fernandes e a problemática educacional: uma leitura (1941-1964). 1997. 232 f. Tese de Doutorado (Educação). Universidade Estadual de Campinas, 1997.

OLIVEIRA, Marcos. Florestan Fernandes. coleção educadores. MEC. Recife: Massangana Editora, 2010.

SAVIANI, Demerval. Florestan Fernandes e a educação. In: Estudos Avançados, São Paulo, n. 26, p. 71-87, jan./abr. 1996.

SOUZA, Patrícia. Florestan Fernandes e os dilemas da democracia no Brasil. In: Perspectiva, São Paulo, v.31, p. 85-96, jan./jun. 2007.

Recebido em 20 de agosto de 2017. Aceito em 09 de fevereiro de 2018. 